Article

\title{
Effect of Inorganic Carbon Concentration on the Development of Subaerial Phototrophic Biofilms on Granite
}

\author{
Daniel Vázquez-Nion *(D), Elsa Fuentes and Beatriz Prieto $\mathbb{D}$ \\ Departamento de Edafoloxía e Química Agrícola, Facultade de Farmacia, Universidade de Santiago de \\ Compostela, 15782 Santiago de Compostela, Spain; elsa.fuentes.alonso@usc.es (E.F.); beatriz.prieto@usc.es (B.P.) \\ * Correspondence: daniel.vazquez@usc.es; Tel.: +34-881814920
}

Received: 9 October 2020; Accepted: 27 October 2020; Published: 29 October 2020

check for updates

\begin{abstract}
Organisms living at the stone-air interface are expected to be affected by changes in the atmospheric composition due to greenhouse gases emissions. Increased $\mathrm{CO}_{2}$ concentrations may particularly affect phototrophic microorganisms that colonize stone cultural heritage and form subaerial biofilms. However, little is known about the effects of the environmental changes on microorganisms that colonize stone and the consequences for cultural heritage conservation. In the present study, we investigated how an increase in inorganic carbon concentration affected the development of a subaerial biofilm composed by the cyanobacterium Synechocystis sp. PCC 6803 grown on granite. For this purpose, we established two experiments on biofilm formation, with and without addition of inorganic carbon to the growth medium. Higher concentrations of carbon promoted biofilm growth and increased the concentrations of the photosynthetic pigments chlorophyll $a$ and carotenoids on granite surface, potentially exacerbating the aesthetic impact of these biofilms on stone-made cultural heritage. However, the extracellular polysaccharides produced were not significantly affected by carbon availability, so that physical stone biodeterioration might not be increased by the cyanobacterial matrix. The findings provide valuable data on how the existing global change scenario might affect organisms inhabiting stone cultural heritage and encourage to develop new sustainable treatments and methodologies to prevent biodeterioration and thus preserve stone cultural heritage.
\end{abstract}

Keywords: biodeterioration; climate change; cultural heritage; cyanobacteria; Synechocystis sp. PCC 6803

\section{Introduction}

The industrial revolution led to a rise in anthropogenic activity which has contributed to increase the concentration of greenhouse gases (GHGs), among which $\mathrm{CO}_{2}$ plays an important role. The concentrations of global $\mathrm{CO}_{2}$ and other gases are expected to continue to increase, in the absence of changes in current production models. Global environmental change is thus expected to occur during the next century, including a mean temperature increase of $0.6-4.0^{\circ} \mathrm{C}$ and changes in precipitation patterns [1]. Increased levels of pollutants and changes in temperature and precipitation patterns will affect all types of materials exposed to the environment, including built cultural heritage, which is generally neither prepared for nor adapted to the future climate variation. As a considerable proportion (20-30\%) of the degradation of monuments is due to biological activity [2,3], study of the interactions between organisms and the changing environment is of utmost importance in order to anticipate the possible deterioration that this may entail [4]. Algae or cyanobacteria are usually the first colonizers of bare stone due to their availability to fix $\mathrm{CO}_{2}$, and they provide organic matter that enables the subsequent colonization of heterotrophs [5]. These microorganisms can form subaerial 
biofilms, which are microbial mats that grow at the stone-air interface within a matrix of self-produced extracellular polymeric substances (EPS) [6,7]. These complex communities can develop on stone cultural heritage and interact with the atmosphere and the stone surface [8]. The EPS produced by biofilms can lead to the alteration of the stone's pore size distribution due to mechanical stresses caused by shrinking and swelling cycles of the colloidal biogenic slimes. This result in variations of the moisture circulation patterns and temperature response [9]. The microorganisms in subaerial biofilms are in constant, direct contact with the environment and must; therefore, respond to changes in climate conditions, which in turn makes them extremely tolerant and resistant to extreme conditions $[10,11]$. Variations in atmospheric $\mathrm{CO}_{2}$ levels may affect the physiology of these microorganisms, which can use $\mathrm{CO}_{2}$ as a source of carbon. The growth of organisms can be enhanced by $\mathrm{CO}_{2}$ [12-14], which can have a fertilizing effect on photosynthetic organisms due to its importance in the production of nutrients [15-17]. However, the way that communities respond to changes in $\mathrm{CO}_{2}$ concentration is difficult to predict and is species dependent, with different types of organisms responding differently to the same stimulus [18,19].

Variations in climate are; therefore, expected to have an important effect on the colonizing species of the heritage, as this will affect the environmental factors that regulate internal biological processes, modifying their metabolism and both deteriorative and protective activity $[20,21]$. However, there is a lack of information about how environmental variations, especially those related to climate change, affect subaerial biofilms, together with the importance in relation to cultural heritage conservation. The vast majority of studies refer to freshwater environments, and the existing literature on the effect of climate change is extremely limited, particularly regarding the effect of $\mathrm{CO}_{2}$ on subaerial biofilms that colonize stone heritage. In this study, we investigated how an increase in atmospheric $\mathrm{CO}_{2}$ concentrations might affect the formation of a subaerial biofilms composed by the cyanobacterium Synechocystis sp. PCC 6803 grown on granite. For this purpose, biofilms were grown in the laboratory in medium with or without inorganic carbon added. Biomass, photosynthetic pigment composition, EPS production and oxidative stress of the biofilms formed were measured to study how the existing global change scenario might affect the photosynthetic organisms inhabiting the stone cultural heritage and shed light on the needs for its future conservation.

\section{Materials and Methods}

\subsection{Lithotype Studied}

The stone used in the study is a two-mica adamellitic granite denominated Silvestre. It is mainly composed by quartz, K-feldspar, plagioclases, biotite, muscovite and chlorite, with an equigranular-panallotriomorphic texture of medium grain [22]. The granite was cut with a diamond blade to produce samples of size $7 \times 2 \times 1 \mathrm{~cm}^{3}$, which were used as the substrate for subaerial biofilm formation.

\subsection{Strain Studied and Culture Conditions}

The microorganism used to form biofilms in the laboratory was the photoautotrophic cyanobacterium Synechocystis sp. PCC 6803 (ATCC 27184). This species was used in the protocol developed by [23] for subaerial biofilm formation due to its fast-growing capacity, which makes it a model organism for studying the biofilm responses to environmental changes. Axenic batch cultures were grown in BG11 medium [24] at room temperature and under natural illumination for a period of one month.

\subsection{Procedure for Biofilm Formation in the Laboratory}

A drip flow reactor (DFR, Biosurface Technology Corp., Bozeman, MT, USA) modified with a glass lid was used to reproduce subaerial biofilm growth at the stone-air interface, based on the protocol developed by [23]. Individual stationary-phase cultures of Synechocystis sp. PCC 6803 were 
centrifuged at $4500 \mathrm{rpm}$ for $15 \mathrm{~min}$ and were then resuspended in modified BG11 medium adjusted to produce a cell concentration of $10^{7}$ cell $\mathrm{ml}^{-1}$. Twenty $\mathrm{ml}$ of the planktonic culture was added to each DFR channel, which also held a granite tile. The reactor was placed in a flat position and left for $24 \mathrm{~h}$ at room temperature under a 14:10 light:dark photoperiod of $30 \mu \mathrm{mol}$ photon $\mathrm{m}^{-2} \mathrm{~s}^{-1}$ illumination (Lumilux T8, Osram, Berlin, Germany). After $24 \mathrm{~h}$ in batch mode, the reactor was drained by placing it on a surface at an angle of $10^{\circ}$. The DFR was then attached to the medium reservoir and fresh medium (modified BG11) was pumped through each channel at a rate of $12 \mathrm{~mL} \mathrm{~h}^{-1}$. The reactor was operated in continuous flow mode for 20 days at room temperature, under the above-described illumination conditions. The medium used in batch and continuous flow modes was BG11 medium modified in two different ways. Half of the samples were treated with BG11 depleted of $\mathrm{Na}_{2} \mathrm{CO}_{3}$ so that the only inorganic carbon source for cyanobacteria was that derived from atmospheric $\mathrm{CO}_{2}$. The remaining samples were treated with BG11 enriched with $1 \mathrm{mM} \mathrm{Na}_{2} \mathrm{CO}_{3}$ [25] to provide an extra inorganic source of carbon. The $\mathrm{pH}$ of both media was adjusted to 7.2. The granite tiles were sampled 1 (batch mode), 3 , 7, 14 and 21 days after inoculation to assess biofilm growth. Biofilm growth in the DFR was repeated in triplicate with different inoculum cultures.

\subsection{Assessment of Biofilm Development}

Granite tiles sampled from the reactor were aseptically placed in $50 \mathrm{~mL}$ Falcon tubes containing $10 \mathrm{~mL}$ phosphate buffered saline (PBS, $10 \mathrm{mM}$ phosphate buffer, $0.3 \mathrm{M} \mathrm{NaCl} \mathrm{pH} 7.4$ at $25{ }^{\circ} \mathrm{C}$, Sigma-Aldrich). The tubes were bath sonicated for $2 \mathrm{~min}$ and vortexed for $30 \mathrm{~s}$. Remaining sessile cells were dislodged from the stone by brushing the surface with a sterile brush. The dislodged biofilms were homogenized (Ultra Turrax IKA T1 Basic) at 10,000 rpm for $30 \mathrm{~s}$ and mixed by vortexing for $30 \mathrm{~s}$. Aliquots of biofilm suspension were used in further analyses.

\subsubsection{Biomass Quantification}

Viable cyanobacterial cell counts within the established subaerial biofilms were determined by plate counts. The biofilm suspension was serially diluted in PBS and drop-plated [26] on agar containing BG11 medium. The plates were left for 2-3 days at room temperature under illumination. The colonies were then counted, and the number of $\mathrm{CFU}$ per $\mathrm{cm}^{2}$ was calculated.

\subsubsection{Determination of Photosynthetic Pigments}

For quantification of chlorophyll (chl) $a$ and carotenoids, $1 \mathrm{~mL}$ of biofilm suspension was centrifuged at $6000 \mathrm{rpm}$ for $10 \mathrm{~min}$ and the pellet was resuspended in $1 \mathrm{~mL}$ of dimethylsulfoxide (DMSO). The suspension was heated at $65^{\circ} \mathrm{C}$ for $1 \mathrm{~h}$ with shaking. The extract was then filtered and the absorbance was measured in a UV/Visible spectrophotometer (Jenway 7315); the equations proposed by [27] were used to calculate the chl $a$ and carotenoids contents.

\subsubsection{Assessment of Oxidative Stress}

Cells in $1 \mathrm{~mL}$ of biofilm suspension were broken by sonication (three $1 \mathrm{~min}$ sonication cycles followed by $30 \mathrm{~s}$ cooling periods, with Bandelin Sonopuls HD2070) to determine the reactive oxygen species (ROS) content. The level of oxidative stress was determined using the $2^{\prime}, 7^{\prime}$-dichlorodihydrofluorescein diacetate $\left(\mathrm{H}_{2}\right.$ DCFDA) assay according to [28]. $\mathrm{H}_{2}$ DCFDA was added to the sonicated suspension to a final concentration of $10 \mu \mathrm{M}$ and incubated at $30^{\circ} \mathrm{C}$ for $30 \mathrm{~min}$ with shaking. The suspension was then centrifuged at 13,000 rpm for $5 \mathrm{~min}$ and the fluorescence (excitation at $485 \mathrm{~nm}$, emission at $535 \mathrm{~nm}$ ) of the supernatant was measured (Tecan Infinite 200 PRO Microplate Reader). Fluorescence values were normalized to the number of cells. 


\subsubsection{Determination of Extracellular Polymeric Substances (EPS)}

Aliquots $(2 \mathrm{~mL})$ of biofilm suspension were centrifuged at $6000 \mathrm{rpm}$ for $10 \mathrm{~min}$ and the resulting pellet was resuspended in $1 \mathrm{~mL}$ of $2 \%$ ethylenediaminetetraacetic acid (EDTA). The suspensions were homogenized at 10,000 rpm for $30 \mathrm{~s}$ and incubated with shaking for $3 \mathrm{~h}$ at $4{ }^{\circ} \mathrm{C}$, before being centrifuged for $20 \mathrm{~min}, 5000 \mathrm{rpm}$ at $4{ }^{\circ} \mathrm{C}$. The carbohydrate fraction of the filtered supernatant containing the EPS was quantified spectrophotometrically by the phenol-sulfuric acid method [29], with $\mathrm{D}(+)$-glucose as standard.

\subsubsection{Statistical Analyses}

Analysis of variance (ANOVA) was applied via SPSS Statistics v19.0 (IBM) software to statistically determine any significant differences between the samples. Differences were considered significant at $p \leq 0.05$.

\subsection{Biofilm Imaging by Confocal Laser Scanning Microscopy (CLSM)}

Granite tiles sampled 21 days after inoculation were observed by CLSM. Samples were stained with the lectin ConA-Texas Red conjugate (Invitrogen) according to [23]. Confocal images were collected using a Nikon A1 laser scanning confocal microscope and a 40× (0.75 NA) Plan Apo $\lambda$ objective. Observations were made in randomized areas of each biofilm: ConA-Texas Red (excitation, $561 \mathrm{~nm}$; emission, 570-620 nm) targeting polysaccharide components of the EPS was recorded in the green channel and chlorophyll autofluorescence of cyanobacterial cells (excitation, $633 \mathrm{~nm}$; emission, $650-750 \mathrm{~nm}$ ) was recorded in the red channel. Captured images were analyzed with the software ImageJ v.1.52o (https://imagej.nih.gov/ij/).

\section{Results}

Synechocystis sp. PCC 6803 cells formed visible subaerial biofilms on granite samples in the DFR (Figure 1). Samples observed under CLSM showed agglomerations of cyanobacterial cells homogeneously distributed and surrounded by EPS, both in biofilms grown in carbon-enriched and non-enriched environments (Figure 2). 


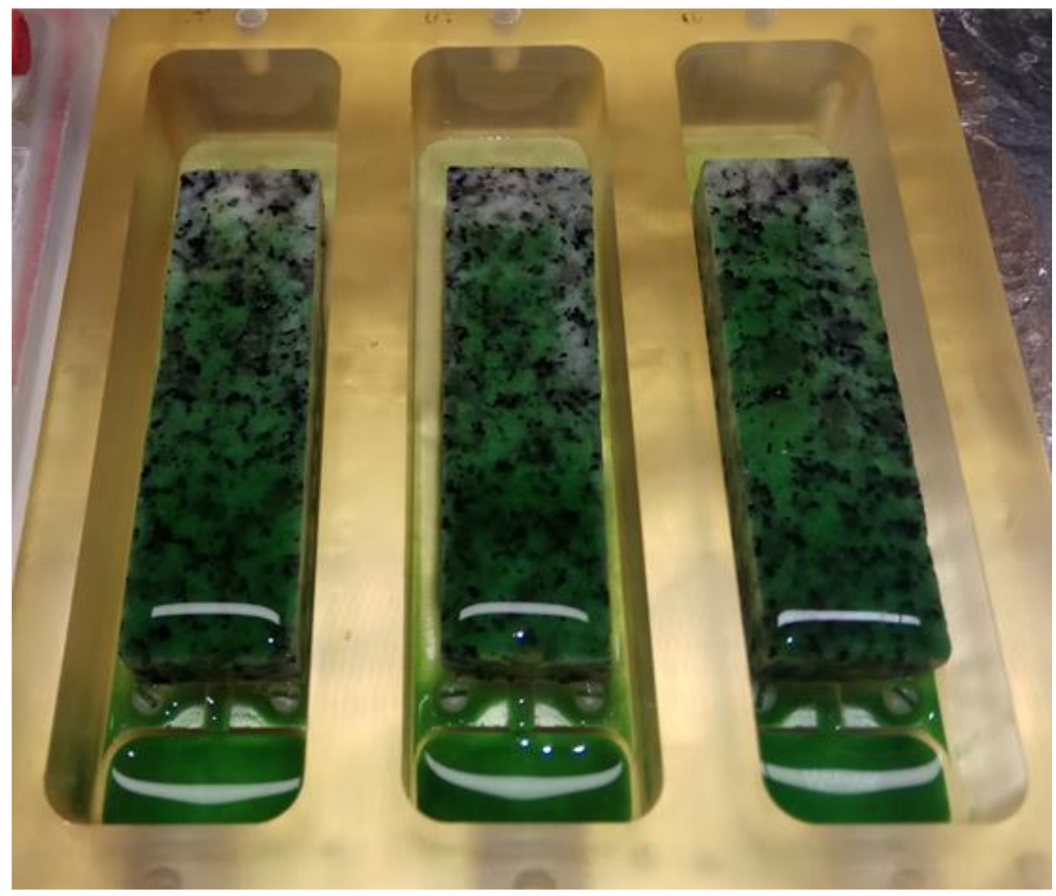

Figure 1. Biofilms formed on granite samples after incubation for 21 days in a drip flow reactor with carbon-enriched medium.
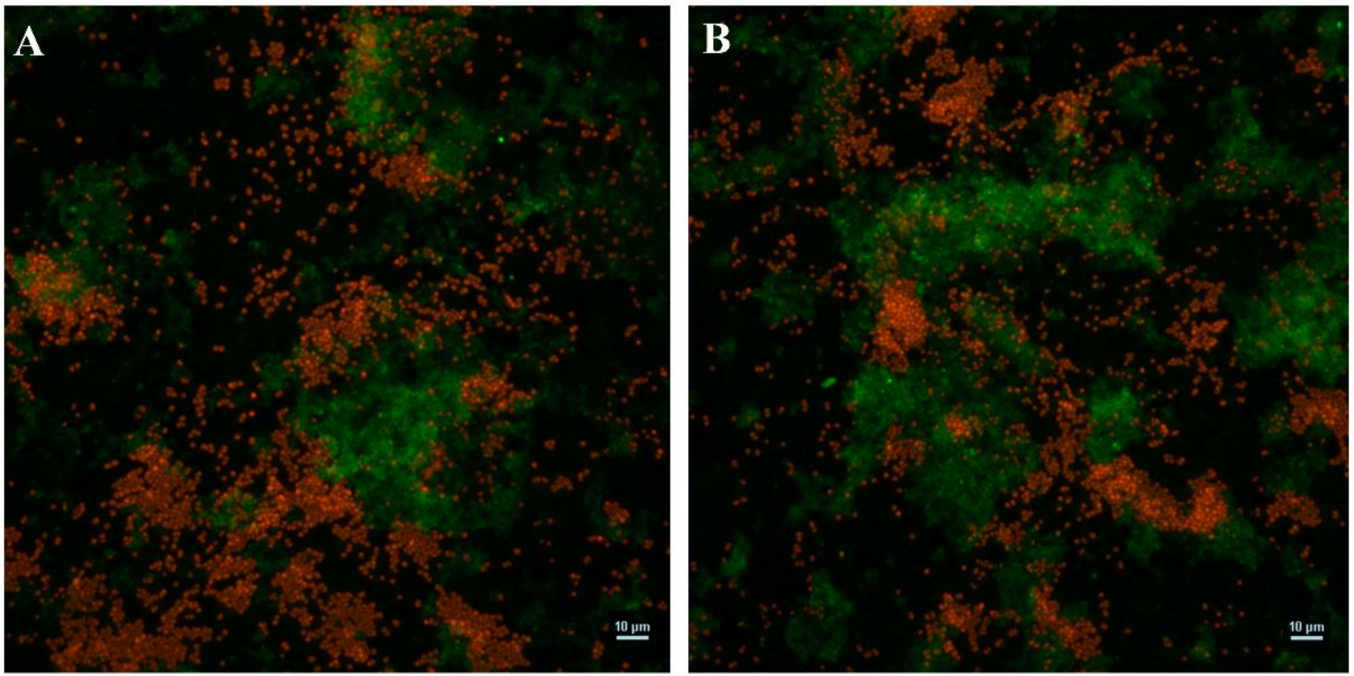

Figure 2. Maximum fluorescence $\mathrm{Z}$ projections of confocal laser scanning microscopy (CLSM) images of biofilms grown for 21 days in (A) medium enriched with inorganic carbon and (B) non-enriched medium. Red: Chlorophyll autofluorescence; green: EPS dyed with ConA-Texas Red.

The effects of incubation time and the addition of inorganic carbon in the medium on the characteristics studied of the biofilms formed are shown in Table 1. The concentration of inorganic carbon in the medium significantly affected growth in terms of cell counts and concentrations of photosynthetic pigments (chl $a$ and carotenoids) per area. The pigments production per CFU, as well as the level of oxidative stress and the extracellular polysaccharides production were not significantly affected. Number of cells, pigments production and EPS also varied significantly throughout the incubation time. Interactions between time and carbon concentration only affected chl $a$ and carotenoids production. 
Table 1. ANOVA of the characteristics of the biofilms studied, considering the incubation time and the addition of inorganic carbon in the medium as factors. $p$-values $\leq 0.05$ are indicated in bold type.

\begin{tabular}{lccc}
\hline Variable $\backslash$ Factor & Time & $\mathbf{C O}_{2}$ & Time $\times \mathbf{C O}_{2}$ \\
\hline $\mathrm{CFU} \cdot \mathrm{cm}^{-2}$ & $<\mathbf{0 . 0 0 1}(F=41.3)$ & $\mathbf{0 . 0 2 7}(F=5.7)$ & $0.149(F=1.9)$ \\
$\mathrm{Chl} a \mu \mathrm{g} \cdot \mathrm{cm}^{-2}$ & $<\mathbf{0 . 0 0 1}(F=113.1)$ & $\mathbf{0 . 0 0 5}(F=10.0)$ & $\mathbf{0 . 0 3 1}(F=3.3)$ \\
$\mathrm{Chl} a \mu \mathrm{g} \cdot \mathrm{CFU}^{-1}$ & $<\mathbf{0 . 0 0 1}(F=12.5)$ & $0.457(F=0.6)$ & $\mathbf{0 . 0 3 2}(F=3.3)$ \\
Carotenoids $\mu \mathrm{g} \cdot \mathrm{cm}^{-2}$ & $<\mathbf{0 . 0 0 1}(F=174.0)$ & $\mathbf{0 . 0 0 4}(F=10.7)$ & $\mathbf{0 . 0 1 2}(F=4.3)$ \\
Carotenoids $\mu \mathrm{g} \cdot \mathrm{CFU}^{-1}$ & $<\mathbf{0 . 0 0 1}(F=15.0)$ & $0.247(F=1.4)$ & $\mathbf{0 . 0 2 9}(F=3.4)$ \\
$\mathrm{ROS}$ rel. units $\cdot \mathrm{CFU}^{-1}$ & $0.300(F=1.3)$ & $0.071(F=3.6)$ & $0.244(F=1.5)$ \\
$\mathrm{EPS} \mu \mathrm{g}$ & $<\mathbf{0 . 0 0 1}(F=14.5)$ & $0.099(F=3.0)$ & $0.070(F=2.6)$ \\
carbohydrate$\cdot \mathrm{cm}^{-2}$ & $<\mathbf{0 . 0 0 1}(F=10.0)$ & $0.203(F=1.7)$ & $0.565(F=0.8)$ \\
$\begin{array}{l}\mathrm{EPS} \mu \mathrm{g} \\
\text { carbohydrate } \cdot \mathrm{CFU}^{-1}\end{array}$ & & & \\
\hline $\mathrm{CFU}$ & &
\end{tabular}

CFU: colony forming units; chl: chlorophyll; ROS: reactive oxygen species; EPS: extracellular polymeric substances.

After an initial $24 \mathrm{~h}$ in batch mode, the number of cyanobacterial cells attached to granite samples was similar at low $C$ concentration $\left(6.16 \pm 0.12 \log _{10} \mathrm{CFU} \cdot \mathrm{cm}^{-2}\right)$ and high $\mathrm{C}$ concentration $(6.13 \pm$ $0.06 \log _{10}$ CFU $\cdot \mathrm{cm}^{-2}$ ) in the medium (Figure 3). Biofilms formed rapidly after two days in drip flow conditions, up to $6.79 \pm 0.15 \log _{10} \mathrm{CFU} \cdot \mathrm{cm}^{-2}$ at low $\mathrm{C}$ concentration and up to $6.81 \pm 0.23 \log _{10} \mathrm{CFU} \cdot \mathrm{cm}^{-2}$ at high $C$ concentration. Differences in biofilm growth began after 14 days of incubation, when biofilms grown under low $\mathrm{C}$ concentration seemed to have reached a steady state, whereas biofilms grown under high $\mathrm{C}$ concentration kept growing. At the end of the experiment (i.e., after 21 days), the number of cyanobacterial cells in biofilms grown at the high $C$ concentration $\left(7.15 \pm 0.09 \log _{10} \mathrm{CFU} \cdot \mathrm{cm}^{-2}\right)$ was higher than in the biofilms grown at the low $\mathrm{C}$ concentration $\left(6.88 \pm 0.07 \log _{10} \mathrm{CFU} \cdot \mathrm{cm}^{-2}\right)$.



Figure 3. Biofilm growth in non-enriched medium and in medium enriched with inorganic carbon. Data are expressed as mean values of three independent replicates (error bars indicate standard deviations).

The amounts of photosynthetic pigments per area were also significantly affected by the different inorganic carbon concentrations (Table 1, Figure 4A). In both experiments, the chl $a$ and carotenoids concentrations in biofilms were similar during the first 14 days of incubation, but after 21 days, the total chl $a$ and carotenoids produced by biofilms grown at high $C$ concentration $(2.83 \pm 0.14$ and $0.84 \pm 0.05 \mu \mathrm{g} \cdot \mathrm{cm}^{-2}$, respectively) were higher than those produced by biofilms grown at the low C concentration $\left(2.01 \pm 0.39\right.$ and $0.62 \pm 0.14 \mu \mathrm{g} \cdot \mathrm{cm}^{-2}$, respectively). Otherwise, the effect of carbon availability on the pigment production per CFU was not statistically significant (Table 1, Figure 4B). The high deviations between replicates could be under the absence of significant effects. These results indicate that higher carbon concentrations did not enhance chl $a$ and carotenoids production in each cell but, as biomass growth was enhanced (Table 1, Figure 3), the concentrations of pigments per area of the stone increased in the carbon-enriched environment. 

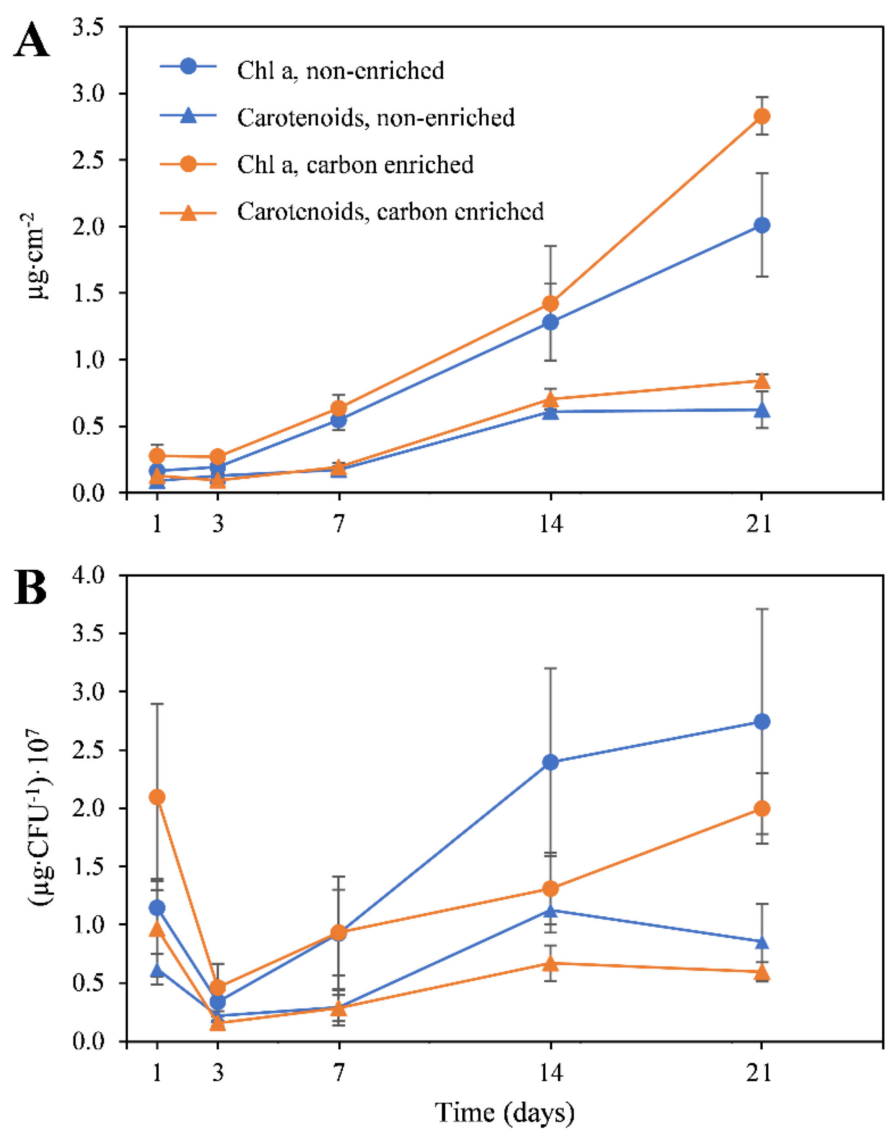

Figure 4. (A) Photosynthetic pigments concentration on granite surface and (B) photosynthetic pigments production per cell in biofilms grown in non-enriched medium and in medium enriched with inorganic carbon. Data are expressed as mean values of three independent replicates (error bars indicate standard deviations).

Regarding levels of oxidative stress, the ROS concentrations in biofilms throughout the experiments are shown in Figure 5. High deviations between replicates were observed, so that ANOVA did not reveal any significant differences, as neither the amount of carbon in the medium nor the incubation time significantly affected the ROS content of the biofilms (Table 1).

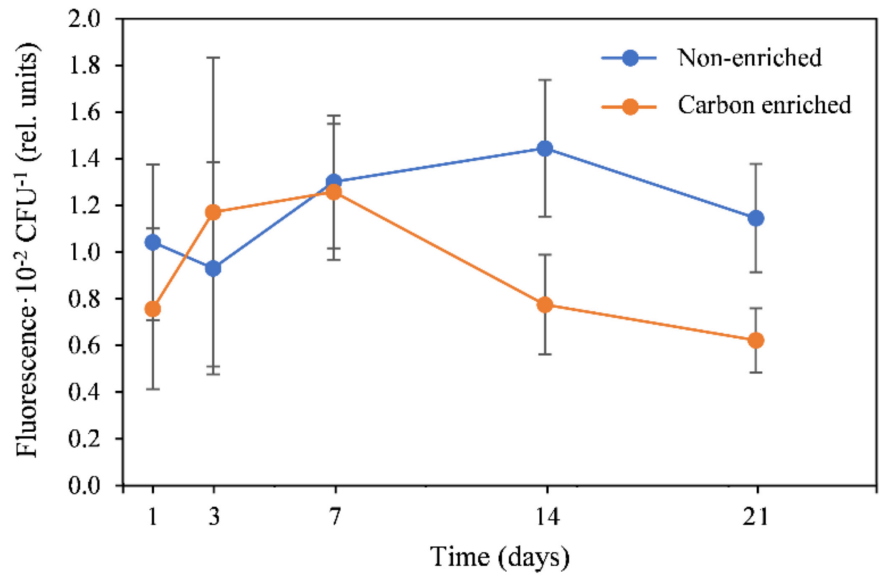

Figure 5. ROS in biofilms grown in non-enriched medium and in medium enriched with inorganic carbon. Data are expressed as mean values of three independent replicates (error bars indicate standard deviations). 
EPS produced by biofilms, measured as the carbohydrate fraction, did not differ clearly in the two experiments, in relation to either the total or relative number of CFU (Figure 6). For biofilms grown with the low carbon concentration, the total EPS ranged from $0.79 \pm 0.14 \mu \mathrm{g} \cdot \mathrm{cm}^{-2}$ after initial $24 \mathrm{~h}$ under batch conditions to $2.44 \pm 0.51 \mu \mathrm{g} \cdot \mathrm{cm}^{-2}$ after 21 days of incubation. For biofilms grown in carbon-supplemented medium, the values ranged from $0.92 \pm 0.24$ to $2.11 \pm 0.47 \mu \mathrm{g} \cdot \mathrm{cm}^{-2}$, respectively. Both low and high carbon concentration conditions led to higher production of EPS per CFU at the attachment phase, with a subsequent decrease in this measure under medium flow. Thus, the incubation time significantly affected EPS production, but carbon concentration was not a significant factor (Table 1).


Figure 6. (A) EPS (carbohydrate fraction) concentration on granite surface and (B) EPS production per cell in biofilms grown in non-enriched medium and in medium enriched with inorganic carbon. Data are expressed as mean values of three independent replicates (error bars indicate standard deviations).

\section{Discussion}

Cyanobacteria are pioneering organisms in many habitats. They can also be easily genetically modified, making them valuable research models in many research areas. More specifically, Synechocystis sp. PCC 6803 has been widely studied and is considered a model organism for studying the effect of stress on metabolism and physiology [30]. In the present study, subaerial biofilms of Synechocystis sp. PCC 6803 were successfully grown on granite in a DFR under conditions characterized by two different levels of carbon availability. Biofilms growth was enhanced and pigments concentration was higher in biofilms exposed to higher carbon concentration, suggesting that the level of atmospheric $\mathrm{CO}_{2}$ may be a limiting factor for subaerial biofilm development.

Previous data on cyanobacterial growth under different carbon concentrations outside the aquatic environment are scarce. Although inorganic carbon seems to maximize growth of freshwater cyanobacteria under favorable conditions, its effect is limited by other factors such as humidity, light 
and nutrient concentrations. For example, an increase in the performance of Synechocystis sp. in a $\mathrm{CO}_{2}$-rich environment was observed, relative to atmospheric $\mathrm{CO}_{2}$ levels [31]. However, under nutrient depletion, the effect of increased $\mathrm{CO}_{2}$ on the growth of Microcystis aeruginosa was limited [32]. Growth of species such as Anabaena sp. PCC 7120 [33] and Gloeotrichia natans [34] did not differ in response to different levels of $\mathrm{CO}_{2}$. In other types of environments, in which both water restrictions and different concentrations of $\mathrm{CO}_{2}$ were applied, it was found that although higher levels of atmospheric $\mathrm{CO}_{2}$ may favor the growth of subaerial multispecies phototrophic biofilms, the effect seems to be offset when water availability is limited [35].

Contrasting findings on pigment production in algae and cyanobacteria in environments in which different levels of inorganic carbon are available have been reported. Thus, some studies reported an increase in production [36], but others have reported a reduction in production $[37,38]$. In the present study, higher concentrations of $\mathrm{CO}_{2}$ did not cause an increase the production of photosynthetic pigments per cell. However, as biofilm growth was enhanced, the total amounts of pigments (both chl $a$ and carotenoids) increased per area. The concentration of photosynthetic pigments per area is directly related to the colour change produced by phototrophic biofilms on the stone where they grow [39-41]. These results may; therefore, involve negative impacts regarding the possible effects of an increase in atmospheric $\mathrm{CO}_{2}$ on the stone colonization and biodeterioration processes. An increase in growth of cyanobacterial biofilms and in pigment concentrations may exacerbate the aesthetic impact of these biofilms on stone-made cultural heritage and; therefore, lead to treatments being necessary (e.g., biocide coating [42], laser cleaning [43] or application of natural oils [44]) and/or loss of value. An essential strategy to prevent colonization and subsequent biodeterioration is the selection of appropriate materials for building, ornamental purposes or replacement. In this regard, the bioreceptivity index (BI) [45] can be used as a decision-making tool and considered a new quality factor for the building stone industry.

The study findings showed that extracellular polysaccharides production did not differ significantly in biofilms grown in carbon-enriched and non-enriched environments. The EPS produced by cyanobacteria are mainly composed of polysaccharides [46,47]. An increase in carbon availability is expected to lead to an increase in EPS production [48]. Other studies have shown that EPS production was increased in a Nostoc sp. culture grown in a $\mathrm{CO}_{2}$-rich environment [49], and was attributed to a mechanism allowing cells to get rid excess carbon produced by overflow metabolism of $\mathrm{CO}_{2}$ [50]. However, in the present study carbon supply may not have been in excess of the cell requirements, and EPS production would; therefore, not increase. Moreover, Vázquez-Nion et al. [51,52] have suggested that EPS production in phototrophic subaerial biofilms is required at the initial stage of stone colonization for subsequent growth, but that the amounts of EPS finally produced depend primarily on the requirements and/or capacity of the biofilm-forming microorganisms rather than on the extent of growth achieved.

Different types of stress are known to increase ROS production, as found for Dunaliella sp. microalgae, for which it was observed that the amounts of $\mathrm{H}_{2} \mathrm{O}_{2}$ were higher in the strains grown under $0.03 \%$ of $\mathrm{CO}_{2}$ (near current atmospheric levels) than those grown at $10 \%$ [53]. One of the consequences of stress is an increase in EPS production, to protect the cells [54]. In addition, increased ROS can oxidize membranes and proteins, so that EPS production can occur in an attempt to replace the molecules destroyed [53]. No significant differences in either ROS or EPS production were observed in Synechocystis sp. PCC 6803 biofilms grown in the presence of different concentrations of inorganic carbon. EPS constitute the main physical weathering agent in phototrophic biofilms, as absorption of water and desiccation cause swelling and shrinkage of the biofilm matrix, thus exerting mechanical stress on the mineral structure and finally leading to cracks and fissures in the stone [9]. Therefore, the present findings are particularly important from the point of view of biodeterioration. Although the expected increase in atmospheric $\mathrm{CO}_{2}$ levels may increase the aesthetic impact due to enhanced growth and the subsequent presence of pigments on the stone, this will not necessarily be accompanied by an increase in physical stone biodeterioration caused by the cyanobacterial EPS matrix. 


\section{Conclusions}

This study provided valuable data on how the current global change scenario might affect organisms inhabiting the stone cultural heritage. Results showed that an environment enriched in inorganic carbon promoted growth of the cyanobacterium Synechocystis sp. PCC 6803. Inorganic carbon did not affect chl $a$ and carotenoids production per cell, but a higher growth lead to the presence of higher amounts of photosynthetic pigments on granite surface. By contrast, oxidative stress and extracellular polysaccharides production was not significantly affected by carbon availability. Regarding possible implications for the future conservation of stone cultural heritage, an increase in the aesthetic impact of phototrophic biofilms colonizing buildings and monuments might be expected. However, this will not necessarily lead to an increase in physical biodeterioration. As different microorganisms can respond in different ways to environmental changes, further research should be carried out with other biofilm-forming species and other environmental factors subjected to future variations in the global change scenario. These results should also encourage to develop new sustainable treatments and methodologies to prevent biodeterioration and thus preserve stone cultural heritage.

Author Contributions: Conceptualization, D.V.-N. and B.P.; formal analysis, D.V.-N.; data curation, D.V.-N. and E.F.; writing—original draft preparation, D.V.-N. and E.F.; writing-review and editing, D.V.-N. and B.P.; supervision, B.P. All authors have read and agreed to the published version of the manuscript.

Funding: This study was partly financed through project CGL2016-79778-R (AEI/FEDER, UE) and Xunta de Galicia (ED431 2018/32). D. Vázquez-Nion was financially supported by Postdoctoral Fellowship-Contract from Xunta de Galicia (ED481B/2017/016). E. Fuentes was financially supported by a PhD Fellowship-Contract MICINN-FPI (BES-2017-079927).

Acknowledgments: The authors would like to thank Francesca Cappitelli, Federica Villa and Alberto Rodríguez Casal for their valuable comments and suggestions.

Conflicts of Interest: The authors declare no conflict of interest.

\section{References}

1. Intergovernmental Panel on Climate Change. Climate Change 2014 Mitigation of Climate Change; Cambridge University Press: New York, NY, USA, 2014.

2. Wakefield, R.D.; Jones, M.S. An introduction to stone colonizing micro-organisms and biodeterioration of building stone. Q. J. Eng. Geol. 1998. [CrossRef]

3. Polo, A.; Gulotta, D.; Santo, N.; Di Benedetto, C.; Fascio, U.; Toniolo, L.; Villa, F.; Cappitelli, F. Importance of subaerial biofilms and airborne microflora in the deterioration of stonework: A molecular study. Biofouling 2012, 28, 1093-1106. [CrossRef] [PubMed]

4. Giacomucci, L.; Bertoncello, R.; Salvadori, O.; Martini, I.; Favaro, M.; Villa, F.; Sorlini, C.; Cappitelli, F. Microbial Deterioration of Artistic Tiles from the Façade of the Grande Albergo Ausonia \& Hungaria (Venice, Italy). Microb. Ecol. 2011, 62, 287-298. [CrossRef] [PubMed]

5. Cappitelli, F.; Salvadori, O.; Albanese, D.; Villa, F.; Sorlini, C. Cyanobacteria cause black staining of the National Museum of the American Indian Building, Washington, DC, USA. Biofouling 2012, 28, 257-266. [CrossRef] [PubMed]

6. Gorbushina, A.A. Life on the rocks. Environ. Microbiol. 2007, 9, 1613-1631. [CrossRef] [PubMed]

7. Villa, F.; Stewart, P.S.; Klapper, I.; Jacob, J.M.; Cappitelli, F. Subaerial Biofilms on Outdoor Stone Monuments: Changing the Perspective Toward an Ecological Framework. Bioscience 2016, 66, 285-294. [CrossRef]

8. Villa, F.; Vasanthakumar, A.; Mitchell, R.; Cappitelli, F. RNA-based molecular survey of biodiversity of limestone tombstone microbiota in response to atmospheric sulphur pollution. Lett. Appl. Microbiol. 2015, 60, 92-201. [CrossRef]

9. Warscheid, T.; Braams, J. Biodeterioration of stone: A review. Int. Biodeterior. Biodegrad. 2000, 46, $343-368$. [CrossRef]

10. Gómez-Bolea, A.; Llop, E.; Ariño, X.; Saiz-Jimenez, C.; Bonazza, A.; Messina, P.; Sabbioni, C. Mapping the impact of climate change on biomass accumulation on stone. J. Cult. Herit. 2012, 13, 254-258. [CrossRef]

11. Villa, F.; Cappitelli, F. The ecology of subaerial biofilms in dry and inhospitable terrestrial environments. Microorganisms 2019, 7, 380. [CrossRef] 
12. Korner, C. Biosphere responses to CO2 enrichment. Ecol. Appl. 2000, 10, 1590-1619. [CrossRef]

13. Velu, C.; Cirés, S.; Brinkman, D.L.; Heimann, K. Effect of $\mathrm{CO}_{2}$ and metal-rich waste water on bioproduct potential of the diazotrophic freshwater cyanobacterium, Tolypothrix sp. Heliyon 5. 2019, 4, e01549. [CrossRef] [PubMed]

14. Dineshbabu, G.; Uma, V.S.; Mathimani, T.; Prabaharan, D.; Uma, L. Elevated $\mathrm{CO}_{2}$ impact on growth and lipid of marine cyanobacterium Phormidium valderianum BDU 20041- towards microalgal carbon sequestration. Biocatal. Agric. Biotechnol. 2020, 25, 101606. [CrossRef]

15. Schimel, D.S. Terrestrial ecosystems and the carbon cycle. Glob. Chang. Biol. 1995, 1, 77-91. [CrossRef]

16. DeLucia, E.H.; Hamilton, J.G.; Naidu, S.L.; Thomas, R.B.; Andrews, J.A.; Finzi, A.; Lavine, M.; Matamala, R.; Mohan, J.E.; Hendrey, G.R.; et al. Net primary production of a forest ecosystem with experimental $\mathrm{CO}_{2}$ enrichment. Science 1999, 284, 1177-1179. [CrossRef]

17. Hamilton, J.G.; DeLucia, E.H.; George, K.; Naidu, S.L.; Finzi, A.C.; Schlesinger, W.H. Forest carbon balance under elevated CO2. Oecologia 2002, 131, 250-260. [CrossRef]

18. Walther, G.R. Community and ecosystem responses to recent climate change. Philos. Trans. R. Soc. B Biol. Sci. 2010, 365, 2019-2024. [CrossRef]

19. Raven, J.A.; Gobler, C.J.; Hansen, P.J. Dynamic $\mathrm{CO}_{2}$ and $\mathrm{pH}$ levels in coastal, estuarine, and inland waters: Theoretical and observed effects on harmful algal blooms. Harm. Algae 2020, 91, 101594. [CrossRef]

20. Viles, H.A.; Cutler, N.A. Global environmental change and the biology of heritage structures. Glob. Chang. Biol. 2012, 18, 2406-2418. [CrossRef]

21. Gulotta, D.; Villa, F.; Cappitelli, F.; Toniolo, L. Biofilm colonization of metamorphic lithotypes of a renaissance cathedral exposed to urban atmosphere. Sci. Total Environ. 2018, 639, 1480-1490. [CrossRef]

22. Sanmartín, P.; Silva, B.; Prieto, B. Effect of surface finish on roughness, color, and gloss of ornamental granites. J. Mater. Civ. Eng. 2011. [CrossRef]

23. Villa, F.; Pitts, B.; Lauchnor, E.; Cappitelli, F.; Stewart, P.S. Development of a laboratory model of a phototroph-heterotroph mixed-species biofilm at the stone/air interface. Front. Microbiol. 2015, 6. [CrossRef] [PubMed]

24. Rippka, R.; Deruelles, J.; Waterbury, J.B. Generic assignments, strain histories and properties of pure cultures of cyanobacteria. J. Gen. Microbiol. 1979, 111, 1-61. [CrossRef]

25. Misra, B.B.; De Armas, E.; Tong, Z.; Chen, S. Metabolomic Responses of Guard Cells and Mesophyll Cells to Bicarbonate. PLoS ONE 2015, 10, e0144206. [CrossRef] [PubMed]

26. Herigstad, B.; Hamilton, M.; Heersink, J. How to optimize the drop plate method for enumerating bacteria. J. Microbiol. Methods 2001, 44, 121-129. [CrossRef]

27. Wellburn, A.R. The Spectral Determination of Chlorophylls a and b, as well as Total Carotenoids, Using Various Solvents with Spectrophotometers of Different Resolution. J. Plant Physiol. 1994, 144, 307-313. [CrossRef]

28. Jakubowski, W.; Biliński, T.; Bartosz, G. Oxidative stress during aging of stationary cultures of the yeast Saccharomyces cerevisiae. Free Radic. Biol. Med. 2000, 28, 659-664. [CrossRef]

29. Dubois, M.; Gilles, K.A.; Hamilton, J.K.; Rebers, P.A.; Smith, F. Colorimetric Method for Determination of Sugars and Related Substances. Anal. Chem. 1956, 28, 350-356. [CrossRef]

30. Liu, Z.X.; Li, H.C.; Wei, Y.P.; Chu, W.Y.; Chong, Y.L.; Long, X.H.; Liu, Z.P.; Qin, S.; Shao, H.B. Signal transduction pathways in Synechocystis sp. PCC 6803 and biotechnological implications under abiotic stress. Crit. Rev. Biotechnol. 2015, 35, 269-280. [CrossRef]

31. Verschoor, A.M.; Van Dijk, M.A.; Huisman, J.; Van Donk, E. Elevated CO2 concentrations affect the elemental stoichiometry and species composition of an experimental phytoplankton community. Freshw. Biol. 2013, 58, 597-611. [CrossRef]

32. Verspagen, J.M.H.; Van De Waal, D.B.; Finke, J.F.; Visser, P.M.; Van Donk, E.; Huisman, J. Rising $\mathrm{CO}_{2}$ levels will intensify phytoplankton blooms in eutrophic and hypertrophic lakes. PLoS ONE 2014, 9, e0104325. [CrossRef]

33. Morales, E.; Rodríguez, M.; García, D.; Loreto, C.; Marco, E. Crecimeinto, producción de pigmentos y exopolisacáridos de la cianobacteria Anabaena sp. PCC 7120 en función del pH y $\mathrm{CO}_{2}$. Interciencia 2002, 27, 373-378.

34. Querijero-Palacpac, N.M.; Martinez, M.R.; Boussiba, S. Mass cultivation of the nitrogen-fixing cyanobacterium Gloeotrichia natans, indigenous to rice-fields. J. Appl. Phycol. 1990, 2, 319-325. [CrossRef] 
35. Prieto, B.; Vázquez-Nion, D.; Fuentes, E.; Durán-Román, A.G. Response of subaerial biofilms growing on stone-built cultural heritage to changing water regime and $\mathrm{CO}_{2}$ conditions. Int. Biodeterior. Biodegrad. 2020, 148, 104882. [CrossRef]

36. Xia, J.R.; Gao, K.S. Impacts of elevated $\mathrm{CO}_{2}$ concentration on biochemical composition, carbonic anhydrase, and nitrate reductase activity of freshwater green algae. J. Integr. Plant Biol. 2005, 47, 668-675. [CrossRef]

37. Chen, Y.; Xu, C.; Vaidyanathan, S. Influence of gas management on biochemical conversion of $\mathrm{CO}_{2}$ by microalgae for biofuel production. Appl. Energy 2020, 261. [CrossRef]

38. Gordillo, F.J.L.; Jiménez, C.; Figueroa, F.L.; Niell, F.X. Effects of increased atmospheric $\mathrm{CO}_{2}$ and $\mathrm{n}$ supply on photosynthesis, growth and cell composition of the cyanobacterium Spirulina platensis (Arthrospira). J. Appl. Phycol. 1998, 10, 461-469. [CrossRef]

39. Prieto, B.; Silva, B.; Aira, N.; Álvarez, L. Toward a definition of a bioreceptivity index for granitic rocks: Perception of the change in appearance of the rock. Int. Biodeterior. Biodegrad. 2006, 58, 150-154. [CrossRef]

40. Vázquez-Nion, D.; Sanmartín, P.; Silva, B.; Prieto, B. Reliability of color measurements for monitoring pigment content in a biofilm-forming cyanobacterium. Int. Biodeterior. Biodegrad. 2013, 84, 220-226. [CrossRef]

41. Sanmartín, P.; Vázquez-Nion, D.; Silva, B.; Prieto, B. Spectrophotometric color measurement for early detection and monitoring of greening on granite buildings. Biofouling 2012, 28, 329-338. [CrossRef]

42. Graziani, L.; Quagliarini, E. On the Modelling of Algal Biofouling Growth on Nano-TiO 2 Coated and Uncoated Limestones and Sandstones. Coatings 2018, 8, 54. [CrossRef]

43. Barreiro, P.; Andreotti, A.; Colombini, M.P.; González, P.; Pozo-Antonio, J.S. Influence of the Laser Wavelength on Harmful Effects on Granite Due to Biofilm Removal. Coatings 2020, 10, 196. [CrossRef]

44. Genova, C.; Fuentes, E.; Sanmartín, P.; Favero, G.; Prieto, B. Phytochemical Compounds as Cleaning Agents on Granite Colonized by Phototrophic Subaerial Biofilms. Coatings 2020, 10, 295. [CrossRef]

45. Vázquez-Nion, D.; Silva, B.; Prieto, B. Bioreceptivity index for granitic rocks used as construction material. Sci. Total Environ. 2018. [CrossRef] [PubMed]

46. De Philippis, R.; Sili, C.; Paperi, R.; Vincenzini, M. Exopolysaccharide-producing cyanobacteria and their possible exploitation: A review. J. Appl. Phycol. 2001, 13, 293-299. [CrossRef]

47. Pereira, S.; Micheletti, E.; Zille, A.; Santos, A.; Moradas-Ferreira, P.; Tamagnini, P.; De Philippis, R. Using extracellular polymeric substances (EPS)-producing cyanobacteria for the bioremediation of heavy metals: Do cations compete for the EPS functional groups and also accumulate inside the cell? Microbiology 2011, 157, 451-458. [CrossRef] [PubMed]

48. Cheng, Y.S.; Labavitch, J.M.; Vandergheynst, J.S. Elevated $\mathrm{CO}_{2}$ concentration impacts cell wall polysaccharide composition of green microalgae of the genus Chlorella. Lett. Appl. Microbiol. 2015, 60, 1-7. [CrossRef]

49. Otero, A.; Vincenzini, M. Nostoc (Cyanophyceae) goes nude: Extracellular polysaccharides serve as a sink for reducing power under unbalanced C/N metabolism. J. Phycol. 2004, 40, 74-81. [CrossRef]

50. De Philippis, R.; Vincenzini, M. Exocellular polysaccharides from cyanobacteria and their possible applications. Fems Microbiol. Rev. 1998, 22, 151-175. [CrossRef]

51. Vázquez-Nion, D.; Silva, B.; Troiano, F.; Prieto, B. Laboratory grown subaerial biofilms on granite: Application to the study of bioreceptivity. Biofouling 2017, 33, 24-35. [CrossRef]

52. Vázquez-Nion, D.; Silva, B.; Prieto, B. Influence of the properties of granitic rocks on their bioreceptivity to subaerial phototrophic biofilms. Sci. Total Environ. 2018, 33, 24-35. [CrossRef]

53. Moghimifam, R.; Niknam, V.; Ebrahimzadeh,H.; Hejazi, M.A. The influence of different $\mathrm{CO}_{2}$ concentrations on the biochemical and molecular response of two isolates of Dunaliella sp. (ABRIINW-CH2 and ABRIINW-SH33). J. Appl. Phycol. 2020, 32, 175-187. [CrossRef]

54. Han, P.P.; Shen, S.G.; Guo, R.J.; Zhao, D.X.; Lin, Y.H.; Jia, S.R.; Yan, R.R.; Wu, Y.K. ROS Is a Factor Regulating the Increased Polysaccharide Production by Light Quality in the Edible Cyanobacterium Nostoc flagelliforme. J. Agric. Food Chem. 2019, 67, 2235-2244. [CrossRef] [PubMed]

Publisher's Note: MDPI stays neutral with regard to jurisdictional claims in published maps and institutional affiliations. 